\title{
Evaluation and spatial distribution characteristic analysis of non-point source pollution in Shenyang*
}

\author{
Jing Zhang $\dagger$, Jun-Shi He and Lin-Fei Zhou \\ College of Water Conservancy, Shenyang Agricultural University, \\ Shenyang, 110866, China \\ ${ }^{\dagger}$ E-mail: zhangjingbluesky@163.com
}

\begin{abstract}
Taking township as basic unit, the discharge amount and rate of pollution contribution of TN, TP, NH3-N and COD have been researched with the export coefficient model and equal-standard pollution load method. The types of agricultural non-point sources include agricultural plant, rural life and scattered livestock and poultry farming. Results indicate that the main non-point pollution loads in Shenyang are TN and TP. The main pollution sources of TN and TP are scattered livestock and poultry farming and agricultural plant. Among the townships of Shenyang, the discharge amount of non-point source pollution in Kangping, Faku, Liaozhong and Xinmin is larger than that in Sujiatun, Dongling, Shenbei and Yuhong. The exurban zone of Shenyang is the key area to non-point source pollution control and prevention.
\end{abstract}

Keywords: Agricultural Non-point Source Pollution; Evaluation; Spatial Characteristics; Shenyang.

\section{Introduction}

With the strength of control capacity on point source pollution, the influence of non-point source pollution is more and more serious. The data of the first national pollution sources general investigation shows that the discharge quantity of COD, $\mathrm{N}$ and $\mathrm{P}$ from agriculture production is far more than that from industry and living and becomes the most important pollution source, so preventing and controlling non-point source pollution in order to the sustainable development of modern agriculture and economic society is more important [1].

As a transformation old industrial base, the ecological environment problem of rural areas in Shenyang is obviously lag behind the development of urbanization progress. After the validation control on domestic wastewater and industry pollution from central urban area, the non-point source pollution from suburb agriculture is becoming the main pollution source of water environment pollution in Shenyang. Taking township as basic unit, basing on the estimation

\footnotetext{
${ }^{*}$ The work was partially supported by Liaoning Science and Technology Project (No. 2014212003).
} 
of quantity of pollutant discharged from all kinds of pollution sources, the pollutant areal distributional difference and pollution sources contribution rate have been analyzed in this paper. The results will provide control and prevention basis for non-point source pollution of Shenyang.

\section{Research Method}

\subsection{The export coefficient model}

In view of the simple of model structure and the easy of data acquiring, considering the wide application in our country, the export coefficient model has been selected to estimate the agricultural non-point source pollutant discharge of Shenyang. The model of export coefficient method is as follow [2]:

$$
L_{j}=\sum_{i=1}^{m} E_{i j} A_{i}
$$

Where $j$ is the type of pollution; $m$ is the number of pollution source; $L_{j}$ is the total load capacity of pollution $j, \mathrm{~kg} \cdot \mathrm{a}^{-1} ; E_{i j}$ is the export coefficient of pollution $j$ in the $i$ type of pollution source, $\mathrm{kg} \cdot \mathrm{hm}^{-2} \cdot \mathrm{a}^{-1}$ or $\mathrm{kg} \cdot \mathrm{ca}^{-1} \cdot \mathrm{a}^{-1} ; A_{i}$ is the number of pollution source of $i$ type, such as the area of soil utilization type $\left(\mathrm{hm}^{2}\right)$ or the number of people and domestic animals (ca).

\subsection{Equal-standard pollution load method}

For explaining the potential pollution level of pollution source, the equalstandard pollution load method is frequently used in pollution source evaluation [3]. In this paper, the equal-standard pollution discharge quantity (ESPDQ) and equal-standard pollution load ratio (ESPLR) have been adopted to determine the main pollution load and the main pollution source.

\subsubsection{Equal-standard pollution discharge quantity (ESPDQ)}

ESPDQ is the equal- standard volume of waste water in unit time which contains pollutant; the calculation formula is as follow [4]:

$$
P_{j}=\frac{L_{j}}{C_{0 j}} \times 10^{-6}
$$

Where $P_{j}$ is the ESPDQ of pollutant $\mathrm{j}, \mathrm{m}^{3} / \mathrm{a} ;{ }^{L_{j}}$ is the pure discharge quantity of pollutant $\mathrm{j}, \mathrm{t} / \mathrm{a} ;{ }^{C_{j}}$ is the water quality type standard values of 
pollutant $\mathrm{j}$ based on the water environment function division, which is the surface water environment quality standards GB3838-2002, mg/L.

\subsubsection{Equal-standard pollution load ratio (ESPLR)}

ESPLR is the ratio between ESPLDQ of certain pollutant and ESPLDQ of total pollutant. It reflects the pollution contribution ratio of certain pollutant. The calculation formula is as follow [5]:

$$
K_{j}=\frac{P_{j}}{P_{\text {total }}} \times 100 \%
$$

Where $K_{j}$ is the ESPLR of pollutant $\mathrm{j} ;{ }^{P_{j}}$ is the ESPDQ of pollutant $\mathrm{j}, \mathrm{m}^{3} / \mathrm{a}$; $P_{\text {total }}$ is the ESPDQ of all kinds of pollutant, $\mathrm{m}^{3} / \mathrm{a}$.

\section{Results on Agricultural Non-Point Pollution Load}

\subsection{Data sources}

From related articles it can be known that N, P, NH3-N and COD in non-point source pollution mainly comes from agricultural production, livestock and poultry breeding and rural residential area [6]. So during the estimation of nonpoint source pollutant load, only three factors are considered which are rural life, agricultural planting and scattered livestock and poultry breeding. The number of rural population, the area of agricultural planting and the number of livestock and poultry of each research unit in research period can be obtained from statistical yearbooks.

\subsection{Discharge of agricultural non-point source pollution}

Based on researched results [7] and related articles [2, 8-12], the export coefficient of non-point source pollutant load in Shenyang is determined as table 1. The pollutant estimation results of TN, TP, NH3-N and COD of Shenyang each unit in 2013 can be obtained by export coefficient model, which are listed in table 2. The discharge ratio of different pollutant source and research unit can be seen in Figure 1 and Figure 2 (note: in Figure 2, SJT, DL,SBXQ,YH, LZ,KP, FK,XM are respectively the abbreviation of Sujiatun, Dongling, Shenbeixinqu, Yuhong, Liaozhong, Kangping, Faku and Xinmin).

From the results it can be known that COD mainly comes from livestock and poultry farming, NH3-N mainly comes from rural residential area and land utilization, while TN and TP mainly comes from land utilization and livestock and poultry farming. Among research units, the pollutant load discharge quantity of XM, FK, LZ and KP is larger than that of SJT, DL, SBXQ and YH. 
Table 1. Export coefficient of Shenyang

\begin{tabular}{ccccccccc}
\hline & \multicolumn{2}{c}{$\begin{array}{c}\text { Land } \\
\text { Pollutant }\end{array}$} & \multicolumn{5}{c}{ Livestock and poultry breeding $(\mathrm{kg} / \mathrm{ca} \cdot \mathrm{y})$} & $\begin{array}{c}\text { person } \\
\text { ntilization }\left(\mathrm{kg} / \mathrm{hm}^{2} \cdot \mathrm{y}\right)\end{array}$ \\
\cline { 2 - 9 } & orchard & $\begin{array}{c}\text { dry } \\
\text { farmland }\end{array}$ & $\begin{array}{c}\text { irrigated } \\
\text { land }\end{array}$ & big livestock & pig & sheep & poultry & \\
\hline TN & 2.38 & 29 & 16.08 & 10.21 & 0.74 & 0.4 & 0.04 & 2.14 \\
TP & 0.15 & 0.9 & 2.6 & 0.2179 & 0.1417 & 0.045 & 0.0054 & 0.2142 \\
NH3-N & 0.194 & 2.36 & $/$ & 0.1533 & 0.066 & 0.10074 & 0.0002475 & 0.6643 \\
COD & $/$ & 11.8 & $/$ & 26.28 & 12.288 & 8.541 & 0.06435 & 9.49 \\
\hline
\end{tabular}

Table 2. Estimation results on agricultural non-point pollution of Shenyang unit: $t / a$

\begin{tabular}{cccccccccc}
\hline \multirow{2}{*}{ Pollutant } & \multicolumn{10}{c}{ Research unit } \\
\cline { 2 - 10 } & SJT & DL & SBXQ & YH & LZ & KP & FK & XM & total \\
\hline TN & 3437 & 1325 & 3716 & 1588 & 7439 & 7115 & 9725 & 11515 & 45860 \\
TP & 292 & 91 & 266 & 124 & 514 & 400 & 461 & 822 & 2970 \\
NH3-N & 274 & 202 & 271 & 180 & 542 & 546 & 698 & 959 & 3673 \\
COD & 8927 & 3484 & 8946 & 3832 & 19149 & 22410 & 25992 & 24421 & 117160 \\
\hline
\end{tabular}

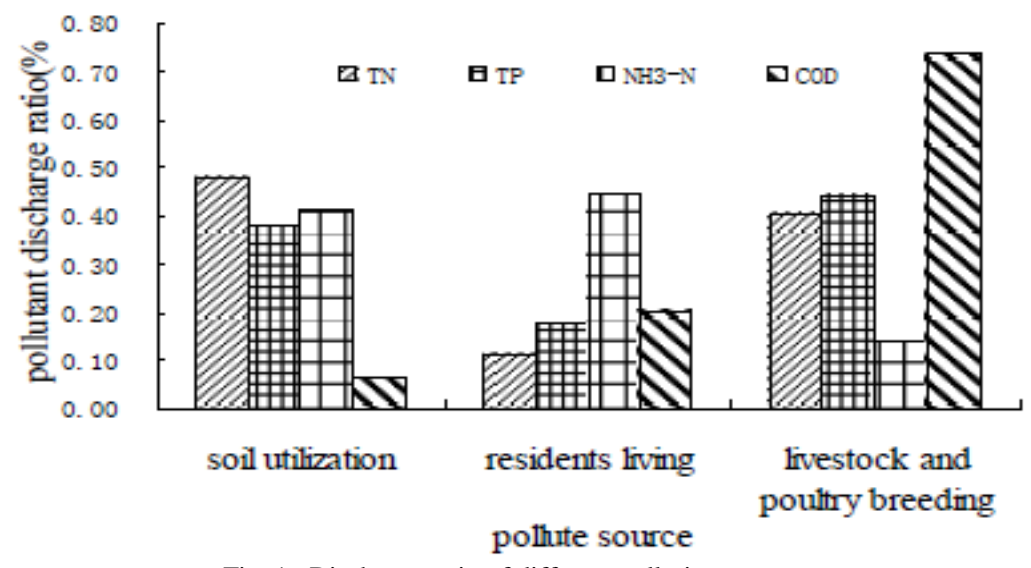

Fig. 1. Discharge ratio of different pollution sources

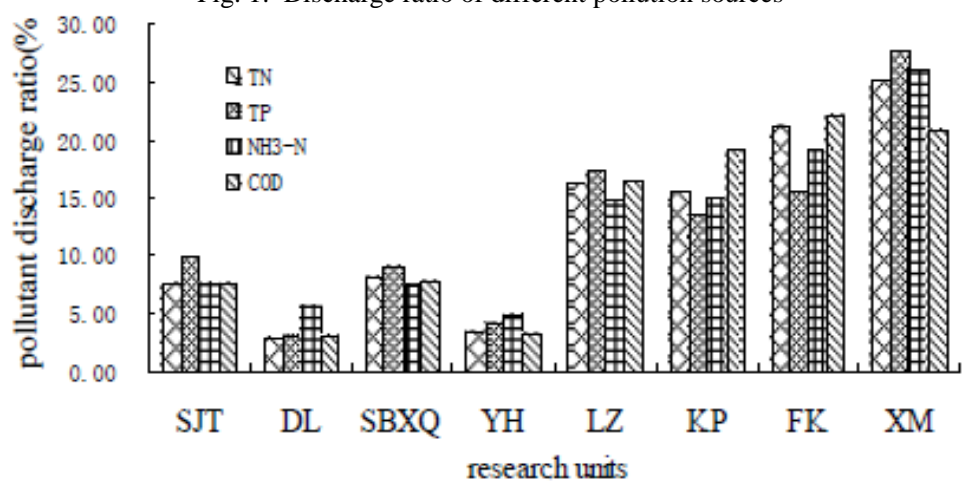

Fig. 2. Discharge ratio of different townships 


\subsection{Equal-standard pollutant discharge of agricultural non-point load}

According to the different urbanization process and water environmental conditions, the water quality in Shenyang surrounding areas such as SJT, DL, SBXQ and YH can be controlled by class III water quality standard, while the water quality in outer suburbs such as LZ, KP, FK and XM should be controlled by class IV. In order to analyze pollution source in the same measure, basing on the water quality control standard of each unit, the equal-standard pollutant discharge quantity in each unit is calculated. According to the surface water environmental quality standard (GB3838-2002), the lower limiting value of TN, TP, NH3-N and COD of class III is respectively 1.0, 0.2, 1.0 and $20 \mathrm{mg} / \mathrm{L}$; the lower limiting value of TN, TP, NH3-N and COD of class IV is respectively 1.5 , $0.3,1.5$ and $30 \mathrm{mg} / \mathrm{L}$, then the equal-standard pollutant load discharge quantity and load discharge ratio of different pollutant and pollution source in each unit can be calculated, the results are listed in Table 3, Table 4 and Table 5 .

From Table 3 it can be seen that the equal-standard pollution discharge quantity of TN and TP is the largest so they are the main pollutant while livestock and poultry farming and agricultural planting are the main pollution sources. From table 4 it can be seen that the main pollution sources are livestock and poultry farming and agricultural planting, the equal-standard pollution load ratio are respectively $42.53 \%$ and $41.47 \%$. Among the units of Shenyang, the pollutant discharge quantity in $\mathrm{XM}$ is the largest; next to it are FK, LZ, KP, SBXQ, SJT, YH and DL. From table 5 it can be seen that TN mainly comes from agricultural planting, TP mainly comes from livestock and poultry farming, and NH3-N mainly comes from rural living while COD mainly comes from livestock and poultry farming.

Table 3. Discharge of agricultural non-point source pollution of Shenyang unit: $\mathrm{m}^{3} \cdot \mathrm{a}^{-1}$

\begin{tabular}{cccccccc}
\hline & \multicolumn{3}{c}{$\begin{array}{c}\text { Equal-standard discharge } \\
\text { quantity of pollutant }\end{array}$} & \multicolumn{3}{c}{$\begin{array}{c}\text { Equal-standard discharge quantity } \\
\text { of pollution source }\end{array}$} \\
\cline { 2 - 8 } & TN & TP & NH3-N COD & $\begin{array}{c}\text { Agricultural } \\
\text { planting }\end{array}$ & Rural life & $\begin{array}{c}\text { Livestock and poultry } \\
\text { breeding }\end{array}$ \\
\hline SJT & 3437 & 1462 & 274 & 446 & 1746 & 965 & 2908 \\
DL & 1325 & 454 & 202 & 174 & 867 & 956 & 333 \\
SBXQ & 3716 & 1330 & 271 & 447 & 1951 & 893 & 2920 \\
YH & 1588 & 618 & 180 & 192 & 1281 & 753 & 544 \\
LZ & 4959 & 1714 & 361 & 638 & 3130 & 1135 & 3408 \\
KP & 4744 & 1335 & 364 & 747 & 2580 & 826 & 3783 \\
FK & 6483 & 1536 & 465 & 866 & 3338 & 1136 & 4877 \\
XM & 7677 & 2740 & 640 & 814 & 6756 & 1685 & 3429 \\
\hline total & 33928 & 11189 & 2758 & 4325 & 21649 & 8349 & 22202 \\
\hline
\end{tabular}


Table 4. Load ratio of agricultural non-point source pollution of Shenyang unit: \%

\begin{tabular}{|c|c|c|c|c|c|c|c|c|}
\hline \multirow[b]{2}{*}{ Unit } & \multicolumn{4}{|c|}{ Equal-standard load ratio } & \multicolumn{3}{|c|}{ Equal-standard load ratio of pollution source } & \multirow[b]{2}{*}{ Total } \\
\hline & $\mathrm{TN}$ & $\mathrm{TP}$ & NH3-N & COD & $\begin{array}{l}\text { Agricultural } \\
\text { planting }\end{array}$ & $\begin{array}{l}\text { Rural } \\
\text { life }\end{array}$ & $\begin{array}{l}\text { Livestock and poultry } \\
\text { breeding }\end{array}$ & \\
\hline SJT & 6.58 & 2.80 & 0.52 & 0.86 & 3.34 & 1.85 & 5.57 & 10.76 \\
\hline DL & 2.54 & 0.87 & 0.39 & 0.33 & 1.66 & 1.83 & 0.64 & 4.13 \\
\hline SBXQ & 7.12 & 2.55 & 0.52 & 0.86 & 3.74 & 1.71 & 5.59 & 11.04 \\
\hline $\mathrm{YH}$ & 3.04 & 1.18 & 0.35 & 0.37 & 2.45 & 1.44 & 1.04 & 4.94 \\
\hline $\mathrm{LZ}$ & 9.50 & 3.28 & 0.69 & 1.22 & 6.00 & 2.17 & 6.53 & 14.70 \\
\hline $\mathrm{KP}$ & 9.09 & 2.56 & 0.70 & 1.43 & 4.94 & 1.58 & 7.25 & 13.77 \\
\hline FK & 12.42 & 2.94 & 0.89 & 1.66 & 6.39 & 2.18 & 9.34 & 17.91 \\
\hline XM & 14.71 & 5.25 & 1.23 & 1.56 & 12.94 & 3.23 & 6.57 & 22.74 \\
\hline total & 65.00 & 21.44 & 5.28 & 8.29 & 41.47 & 15.99 & 42.53 & 100.00 \\
\hline
\end{tabular}

Table 5. Pollution load ratio of different pollution sources in Shenyang unit: \%

\begin{tabular}{ccccc}
\hline \multirow{2}{*}{ Pollutant } & \multicolumn{3}{c}{ Equal-standard load ratio of pollution source } & \multirow{2}{*}{ Total } \\
\cline { 2 - 4 } & Agricultural planting & Rural life & Livestock and poultry breeding & \\
\hline TN & 30.90 & 7.87 & 26.23 & 65.00 \\
TP & 7.92 & 3.94 & 9.58 & 21.44 \\
NH3-N & 2.13 & 2.44 & 0.71 & 5.28 \\
COD & 0.53 & 1.74 & 6.01 & 8.29 \\
\hline total & 41.47 & 15.99 & 42.53 & 100.00 \\
\hline
\end{tabular}

\subsection{Summary of agricultural non-point source pollution in Shenyang}

Through above analysis, we can draw the conclusion that though the discharge quantity of COD is the largest, the main pollutants in Shenyang are TN and TP and they mainly come from livestock and poultry farming and agricultural planting. The reason is that the outer suburb area such as XM, FK, LZ and KP is the main body of Shenyang area, which makes up about $73 \%$ of the total area of Shenyang. They are also the important agriculture district in Shenyang, the planting area of these four units make up 55\% of the total area of the four units and make up $78 \%$ of the total planting area of Shenyang; the orchard area of the four units takes up $65 \%$ of the total orchard area of Shenyang. The numbers of pig, cattle, sheep and poultry in the four units respectively take up 79\%, 84\%, $82 \%$ and $54 \%$ of the total number of them. So the four units are the key area to prevent and control the non-point source pollution. Adjusting the agricultural planting mode and accelerating intensification and modernization of livestock and poultry farming may be the key factors to decrease the agricultural nonpoint source pollution in Shenyang.

\section{Conclusions}

In this paper, the export coefficient method and equal-standard pollution load method have been used to analyze the agricultural non-point source pollution of Shenyang. Through calculation, the pollution discharge quantity of TN, TP, 
NH3-N and COD in Shenyang are respectively $4.6 \times 10^{4}, 0.3 \times 10^{4}, 0.4 \times 10^{4}$ and $11.7 \times 10^{4} \mathrm{t} / \mathrm{a}$, the equal-standard pollution discharge quantity of TN, TP, NH3-N and COD are respectively $3.39 \times 10^{4}, 1.12 \times 10^{4}, 0.28 \times 10^{4}$ and $0.43 \times 10^{4} \mathrm{~m}^{3} / \mathrm{a}$.

The main pollutants of agricultural non-point source in Shenyang are TN and TP. The outer suburb areas are still the key areas to the agricultural nonpoint source pollution prevention and control. The results in this paper can provide the basis and reference for agricultural non-point source pollution prevention and control in Shenyang.

\section{References}

1. YANG Lin-zhang, FENG Yan-fang, SHI Wei-ming, et al. Review of the advances and development trends in agricultural non-point source pollution control in China. Chinese Journal of Eco-Agriculture, 21(1):96101(2013).(In Chinese)

2. LIU Rui-min, SHEN Zhen-yao, DING Xiao-wen, et al. Application of export coefficient model in simulating pollution load of non-point source in upper reach of Yangtze River basin. Journal of agro-environment science. 27(2):677-682(2008). (In Chinese)

3. ZHAO Qian, MA Jian, WEN Qing-chun, et al. Load and status quo of agricultural non-point source pollution in DasuheTownship on the upper stream of Hun river. Journal of ecology and rural environment. 26(2):126131(2010). (In Chinese)

4. WANG Xiao-yan. Non-point source pollution and its management. Beijing: China ocean press. (2000). (In Chinese)

5. LIU Wen-li, LI Yu-bin. Concept consideration on the method of equivalent standard pollution load. Liaoning Urban and Rural Environmental Science \& Technology. 20(3):23-26. (2000). (In Chinese)

6. HAO Fang-hua, CHENG Hong-guang, YANG Sheng-tian. Theory method and application of non-point source pollution model. Beijing: China Environmental Science Press. (2006). (In Chinese)

7. ZHANG Jing, HE Jun-shi, ZHOU Fei, et al. Estimation and evaluation of non-point source pollution in the Hunhe river basin. South-to-North water diversion and water science and technology. 9(6):73-77. (2011). (In Chinese)

8. Shen yang Bureau of Statistics. Shenyang statistical yearbook. Beijing: China Statistics Press. (2014). (In Chinese)

9. DING Xiao-wen, LIU Rui-min, and SHEN Zhen-yao. Method for obtaining parameters of export coefficient model using hydrology and water quality data and its application. Journal of Beijing normal university (Natural Science), 42(5):534-538. (2006). (In Chinese) 
10. DING Xiao-wen, SHEN Zhen-yao, and LIU Rui-min. Temporal-spatial changes of non-point source nitrogen in Upper reach of Yangtze River basin. Journal of agro-environment science, 26(3):836-841. (2007). (In Chinese)

11. CAI Ming, LI Huai-en, ZHUANG Yong-tao, et al. Application of modified export coefficient method in polluting load estimation of non-point source pollution. Journal of hydraulic engineering, (7):40-45. (2004). (In Chinese)

12. LONG Tian-yu, LIANG Chang-de, LI Ji-cheng, et al. forecasting the pollution load of non-point sources in ported to the Three Gorges Reservoir. ACTA Scientiae Circumstantiae, 28 (3):574-581. (2008). (In Chinese)

13. SHEN Zhen-yao, LIU Rui-min, YE Min, et al. Characteristic and its changes regulation of non-point source pollution in Upper reach of Yangtze River basin. Beijing: Science Press, (2008). (In Chinese) 